\title{
Effect of Salmonella thyphymurium Infection on the Pharmacokinetics of Ceftriaxone in Sokoto Red Goats
}

\author{
* O. J. Abdulgafar, O.B Shaibu and U.E. Emmanuel \\ Department of Pharmacology, College of Health Sciences, Usmanu Danfodiyo University Sokoto - Nigeria. \\ [*Corresponding author: layidotcom@yahoo.com, GSM +234 (0)8035950558]
}

\begin{abstract}
This study was designed to investigate the effect of Salmonella thyphimurium infection on the plasma kinetics of ceftriaxone in Sokoto red goats. In a randomised two-way study, 10 healthy male goats were divided into two groups of five each, and either received a single intramuscular (IM) injection of $1 \mathrm{~g}$ ceftriaxone only or $1 \mathrm{~g}$ Ceftriaxone plus inoculation with $S$. thyphimurium. Non compartmental pharmacokinetic parameters were measured in plasma samples by microbiological assay using Escherichia. coli as the test organism. The pharmacokinetic parameters of Ceftriaxone alone were as follows: absorption half life $0.509 \pm 0.004 \mathrm{hr}$, elimination half-life $0.580 \pm 0.012 \mathrm{hr}$, maximum plasma concentration $\left(C_{\max }\right) 45.56 \pm 0.191 \mu \mathrm{g} / \mathrm{ml}$, Time to attain $C_{\max } 0.7 \pm 0.123 \mathrm{hr}$, area under the curve(AUC) $144.06 \pm 1.711 \mu \mathrm{g}-\mathrm{hr} / \mathrm{ml}$, area under mean curve (AUMC) $313.46 \pm 6.156 \mu \mathrm{g}-\mathrm{hr} * \mathrm{hr} / \mathrm{ml}$, volum of distribution (Vd) $485.28 \pm 15.725 \mathrm{ml} / \mathrm{kg}, \mathrm{Cl} 578.751 \pm 6.880 \mathrm{ml} / \mathrm{hr} / \mathrm{kg}$, MRT $2.18 \pm 0.020 \mathrm{hr}$. These were significantly influenced by $S$. thyphimurium infection; with the absorption half life as $0.318 \pm 0.084 \mathrm{hr}$, elimination halflife $0.866 \pm 0.113 \mathrm{hr}, \quad$ Cmax $41 \pm 2.915 \mu \mathrm{g} / \mathrm{ml}$, Tmax $0.5 \mathrm{hr}$, AUC 90.14 $\pm 2.952 \mu \mathrm{g}-\mathrm{hr} / \mathrm{ml}$, AUMC $175.84 \pm 6.948 \mu \mathrm{g}-\mathrm{hr} * \mathrm{hr} / \mathrm{ml}, \quad \mathrm{Vd} \quad 1175.36 \pm 181.30 \mathrm{ml} / \mathrm{kg}$, clearance $928.549 \pm 30.675 \mathrm{ml} / \mathrm{hr} / \mathrm{kg}, \quad$ MRT $1.94 \pm 0.060 \mathrm{hr}$. These findings suggest that $S$. thyphimurium infection in Sokoto red goat significantly influences the pharmacokinetics of Ceftriaxone. Further studies are required to buttress these findings and to establish the mechanism of interaction.

Keywords: pharmacokinetics, Salmonella thyphimurium, ceftriaxone, Sokoto red goats.
\end{abstract}

\section{INTRODUCTION}

Ceftriaxone is a third generation cephalosporin that is widely used in bacterial infections. It has a good activity against several strains of Salmonella and its long half life and single daily dosing proffers it with a positive advantage. Several studies have documented pharmacokinetics of ceftriaxone in healthy situation; these parameters may differ in situation of infection due to fever, inflammation and transient dysfunction of the liver and kidneys during the infection (Gopal et al., 1994, Etuk and Onyeyili, 2006). S. thyphimurium infection was shown to alter the distribution of chloramphenicol (Etuk and Onyeyili, 2006) and a fall in peak plasma levels was observed in Pasteurella haemolytica infected calves (Burrows et al., 1986), and Escherichia coli infected veal calves (Groothuis et al., 1979). However, the peak plasma concentration of amoxicillin remained unchanged in $S$. thyphimurium infected pigs (Agerso et al., 2000). Pharmacokinetics of ceftriaxone was affected by pulmonary infection (Wang et al., 2005), and achieved peak abscess levels of about $40 \%$ of the peak serum levels (Dezfulian et al., 1993). Ceftriaxone has been shown to displace phenytoin in serum in vitro and invivo (Dasgupta et al., 1991), and decreased the efficacy of morphine in rats (Rawls et al., 2007). A polyherbal drug (Fibrosin) decreased the body clearance of ceftriaxone (Sar et al., 2006) while the clearance was significantly increased during hemofiltration and hemodialysis (Matzke et al., 2000). Ceftriaxone is extensively used in many bacterial infections, but to the best of our knowledge no data is available for the effect of $S$. thyphimurium infection on the plasma kinetics of ceftriaxone in Sokoto red goats, hence the justification for this study. Therefore, the purpose of this study is to investigate whether $S$. thyphimurium infection has any effect on the pharmacokinetics of ceftriaxone in Sokoto Red Goats. 
MATERIALS AND METHODS Sample collection

(a) Drug: Generic Ceftriaxone injection, Panpharma Laboratories, France.

(b) Animals: Ten apparently healthy male Sokoto red goats aged six to twelve months and weighing $10-13 \mathrm{~kg}$ were purchased from Dange market in Dange-Shuni Local Government Area of Sokoto State, Nigeria. The goats were housed separately in groups of five after a computer generated randomisation and conditioned in pens with concrete floors in the large animal unit of Usmanu Danfodiyo University Sokoto. They were fed on wheat bran, bean offal, cowpea hay, while water was provided ad libitum. Before the commencement of the experiment, the goats were confirmed to be in healthy condition. The animals were acclimatised for a period of two weeks, and evaluated once every 24 hours after purchase for respiratory and pulse rates, rectal temperature and colour of conjunctivae and buccal mucous membrane.

Drug Administration : The first group received $1 \mathrm{~g}$ of ceftriaxone only; the second group received $1 \mathrm{~g}$ of ceftriaxone and inoculation with $S$. thyphimurium. All drugs were administered via the intramuscular route. Venous blood samples collected via the jugular vein $(5 \mathrm{ml})$ were drawn pre-dose and at $0,0.25,0.5,1,1.5,2,2.5,3,4$ , $6,8,12,24$ and 48 hours. The samples were collected in heparinized centrifuge tubes. All the samples were centrifuged and plasma separated and frozen until running the analysis.

Determination of the regression equation for the microbiological assay: Pooled plasma from healthy Sokoto red goats was used as diluents to constitute 2.5, 5, 10, 15,20,25,30,35,40,45 and $50 \mathrm{ug} / \mathrm{ml}$ Ceftriaxone solution. Using the agar well diffusion technique, the inhibition of the growth of Escherichia coli was then identified and measured using a vernier calliper. A regression equation $\mathrm{Y}=\mathrm{ax}+\mathrm{C}$ and correlation co-efficient was then generated from the concentration response curve using Graphpad instat software (Zuluaga et al., 2009, Singh et al., 2008, Issa et al., 2007a).
Infection of sokoto red goats with Salmonella typhimurium: The method of Otesile et al (1990) was used. Stock culture of S. typhimurium initially obtained from clinical isolates was used. Each of the five goats in the second group received orally a $10 \mathrm{ml}$ suspension containing $2 \times 10^{9}$ organism $/ \mathrm{ml}$. Blood was collected aseptically from the goats jugular veins for haematological tests. Clinical features indicating infection were observed and noted in the infected goats as per the pre-validated models.

Pharmacokinetic analysis: Pharmacokinetic parameters were calculated by inputting the concentration time data obtained into the pharmacokinetic software PK Solution 2.0 and curve stripping was performed using the leastsquare technique.

Statistical analysis: The mean, standard error of mean, spearmanô correlation, and p-values were calculated using Graphpad instat, statistical software.

\section{RESULTS}

Table 1 shows mean zones of inhibition, standard error of mean, and spearman⿳亠丷 correlation coefficient of various Ceftriaxone concentrations when tested against several microorganisms to be selected for the microbiological assay.

This study reveals that E. coli is most sensitive to Ceftriaxone of all the organisms tested and has the best correlation when concentration is plotted against respective zones of inhibition and was selected as the assay $(\mathrm{R}=0.9935, \mathrm{p}<0.0001)$.

Table 2 shows plasma Ceftriaxone concentrations against time following a single intramuscular administration in healthy and $S$. thyphimurium infected Sokoto red goats, while Table 3 shows summary of pharmacokinetic parameters of Ceftriaxone in healthy and infected Sokoto red goats.

S. thyphimurium infection in the goats resulted in a rise in rectal temperature, significant reduction in feed intake, passage of frequent watery and offensive faeces, and lethargy, and the haematological examinations revealed a 
significant rise in white blood cell count. Infecting the Sokoto red goats with $S$. thyphimurium caused a fall in the mean maximum plasma concentration $(41 \pm 2.915 \mu \mathrm{g} / \mathrm{ml})$ at about 0.5 hours after drug administration, when compared with the value of mean maximum plasma concentration $(45.56 \pm 0.191 \mu \mathrm{g} / \mathrm{ml})$ obtained in the healthy Sokoto red goats at about 0.7 hours after drug administration $(\mathrm{P}=0.1572)$ (Table 3).

Table 1: Mean zones of inhibition, standard error of mean, and spearmanô correlation coefficient of various ceftriaxone concentrations

\begin{tabular}{llll}
\hline $\begin{array}{l}\text { Concentration of } \\
\text { Ceftraixone } \\
(\mu \mathrm{g} / \mathrm{ml})\end{array}$ & $\begin{array}{l}\text { Zone of Inhibition } \\
\text { of growth of } \\
\text { Klebsiella }(\mathrm{mm})\end{array}$ & $\begin{array}{l}\text { Zone of Inhibition of growth } \\
\text { of E.coli }(\mathrm{mm})\end{array}$ & $\begin{array}{l}\text { Zone of } \\
\text { Inhibition of } \\
\text { growth of } \\
\text { Proteus }(\mathrm{mm})\end{array}$ \\
\hline 2.5 & $20.4 \pm 1.01$ & $24.0 \pm 0.13$ & $23.6 \pm 1.74$ \\
5 & $24.2 \pm 1.20$ & $27.0 \pm 0.12$ & $26.5 \pm 1.02$ \\
10 & $23.0 \pm 1.10$ & $28.5 \pm 1.56$ & $26.6 \pm 1.09$ \\
15 & $25.4 \pm 0.99$ & $31.0 \pm 0.11$ & $28.0 \pm 0.93$ \\
20 & $24.7 \pm 1.12$ & $31.5 \pm 0.16$ & $28.1 \pm 1.02$ \\
25 & $24.8 \pm 1.00$ & $32.0 \pm 0.11$ & $28.3 \pm 2.06$ \\
30 & $24.8 \pm 1.00$ & $33.0 \pm 0.09$ & $28.2 \pm 1.05$ \\
35 & $26.5 \pm 0.63$ & $33.5 \pm 0.08$ & $29.2 \pm 0.84$ \\
40 & $27.0 \pm 1.53$ & $34.2 \pm 0.11$ & $28.7 \pm 1.00$ \\
45 & $26.5 \pm 0.96$ & $34.98 \pm 0.08$ & $29.4 \pm 0.67$ \\
50 & $27.4 \pm 0.74$ & $36.25 \pm 0.11$ & $30.3 \pm 0.47$ \\
$\mathrm{R}^{2}$ & 0.5344 & $* 0.9935$ & 0.5612 \\
\hline
\end{tabular}

All values of $\mathrm{ZI}$ are mean \pm SEM of $\mathrm{n}=6$ observations. $\mathrm{R}=$ Spearmanô Correlation coefficient. *=Selected $\mathrm{R}=0.9935, \mathrm{p}<0.0001$

The plasma concentration of ceftriaxone in both healthy and infected Sokoto red goats showed a steady decline afterwards until minimum measurable plasma concentrations of $1.73 \pm 0.00$ and $1.2 \pm 0.10 \mu \mathrm{g} / \mathrm{ml}$ were obtained at about 6 hours after drug administration respectively (Table 2 ).

The pharmacokinetics behavior of Ceftriaxone in both healthy and infected Sokoto red goats after intramuscular injection could be best described by a one compartment open model with a first order kinetic (Figure 1 and 2).

There was a statistically significant effect on the area under the curve (144.06 \pm 1.711 and $90.14 \pm 2.952 \mu \mathrm{ghr} / \mathrm{ml}$ ), volume of distribution $(485.28 \pm 15.725$ and $1175.36 \pm 181.30 \mathrm{ml} / \mathrm{kg}$ ), clearance $(578.751 \pm 6.880$ and $928.549 \pm 30.675$ $\mathrm{ml} / \mathrm{hr} / \mathrm{kg})$, mean residence time $(2.18 \pm 0.020$ and $1.94 \pm 0.060 \mathrm{hr}) \quad(\mathrm{P}<0.05) \quad$ respectively when pharmacokinetic parameters of the healthy goats were compared with the infected goats (Table 3 ).

Table 2: Plasma concentrations of Ceftriaxone following a single intramuscular administration in healthy and $S$. thyphimurium infected Sokoto red goats

\begin{tabular}{lll}
\hline Time $(\mathrm{hr})$ & $\begin{array}{l}\text { Health Goats } \\
\text { Conc. }(\mu \mathrm{g} / \mathrm{ml})\end{array}$ & $\begin{array}{l}\text { Infected Goats } \\
\text { Conc. }(\mu \mathrm{g} / \mathrm{ml})\end{array}$ \\
\hline 0.25 & $32 \pm 0.51$ & $19 \pm 2.91$ \\
0.5 & $45 \pm 0.45$ & $41 \pm 2.91$ \\
1.0 & $45 \pm 0.17$ & $32 \pm 1.22$ \\
1.5 & $37 \pm 0.38$ & $25 \pm 0.00$ \\
2.0 & $28.5 \pm 0.33$ & $19 \pm 1.00$ \\
2.5 & $27 \pm 0.44$ & $15 \pm 1.58$ \\
3.0 & $25 \pm 0.95$ & $15 \pm 1.58$ \\
4.0 & $19 \pm 0.95$ & $5 \pm 1.58$ \\
6.0 & $1.73 \pm 0.00$ & $1.2 \pm 0.10$ \\
\hline
\end{tabular}

This table shows the mean concentrations \pm SEM against time for all animals in the group $(n=5)$. 
Abdulgafar et al.: Effect of Salmonella thyphymurium Infection on the Pharmacokinetics of Ceftriaxone in......

Table 3: Summary of pharmacokinetic parameters of Ceftriaxone in healthy and infected Sokoto red goats

\begin{tabular}{llll}
\hline PK parameters & $\begin{array}{c}\text { Healthy goats } \\
(\text { mean } \pm \text { sem })\end{array}$ & $\begin{array}{c}\text { Infected goats } \\
(\text { mean } \pm \text { sem })\end{array}$ & P-value \\
\hline Absorption Half life $(\mathrm{hr})$ & $0.509 \pm 0.004$ & $0.318 \pm 0.084$ & $\mathrm{P}=0.053$ \\
Elimination Half life $(\mathrm{hr})$ & $0.580 \pm 0.012$ & $0.866 \pm 0.113$ & $\mathrm{P}=0.0664$ \\
$\mathrm{C}_{\max }(\mu \mathrm{g} / \mathrm{ml})$ & $45.56 \pm 0.191$ & $41 \pm 2.915$ & $\mathrm{P}=0.1572$ \\
$\mathrm{~T}_{\max }(\mathrm{hr})$ & $0.7 \pm 0.123$ & $0.5 \pm 0$ & \\
$\mathrm{AUC}(\mu \mathrm{ghr} / \mathrm{ml})$ & $144.06 \pm 1.711$ & $90.14 \pm 2.952$ & $\mathrm{P}<0.0001$ \\
$\mathrm{AUMC}\left(\mu \mathrm{ghr}{ }^{*} \mathrm{hr} / \mathrm{ml}\right)$ & $313.46 \pm 6.156$ & $175.84 \pm 6.948$ & $\mathrm{P}<0.0001$ \\
$\mathrm{Vd}(\mathrm{ml} / \mathrm{kg})$ & $485.28 \pm 15.725$ & $1175.36 \pm 181.30$ & $\mathrm{P}=0.0053$ \\
$\mathrm{Cl}(\mathrm{ml} / \mathrm{hr} / \mathrm{kg})$ & $578.751 \pm 6.880$ & $928.549 \pm 30.675$ & $\mathrm{P}<0.0001$ \\
MRT $(\mathrm{hr})$ & $2.18 \pm 0.020$ & $1.94 \pm 0.060$ & $\mathrm{P}=0.0162$ \\
\hline
\end{tabular}

Key: $\mathrm{C}_{\max }=$ maximium plasma concentration; $\mathrm{T}_{\max }=$ time to attain the $\mathrm{C}_{\max } ; \mathrm{AUC}=$ area under the curve (area under the concentration-time curve); $\mathrm{AUMC}=$ area under the mean curve; $\mathrm{Vd}=$ volume of distribution; $\mathrm{Cl}=$ clearance; $\mathrm{MRT}=$ mean resident time.

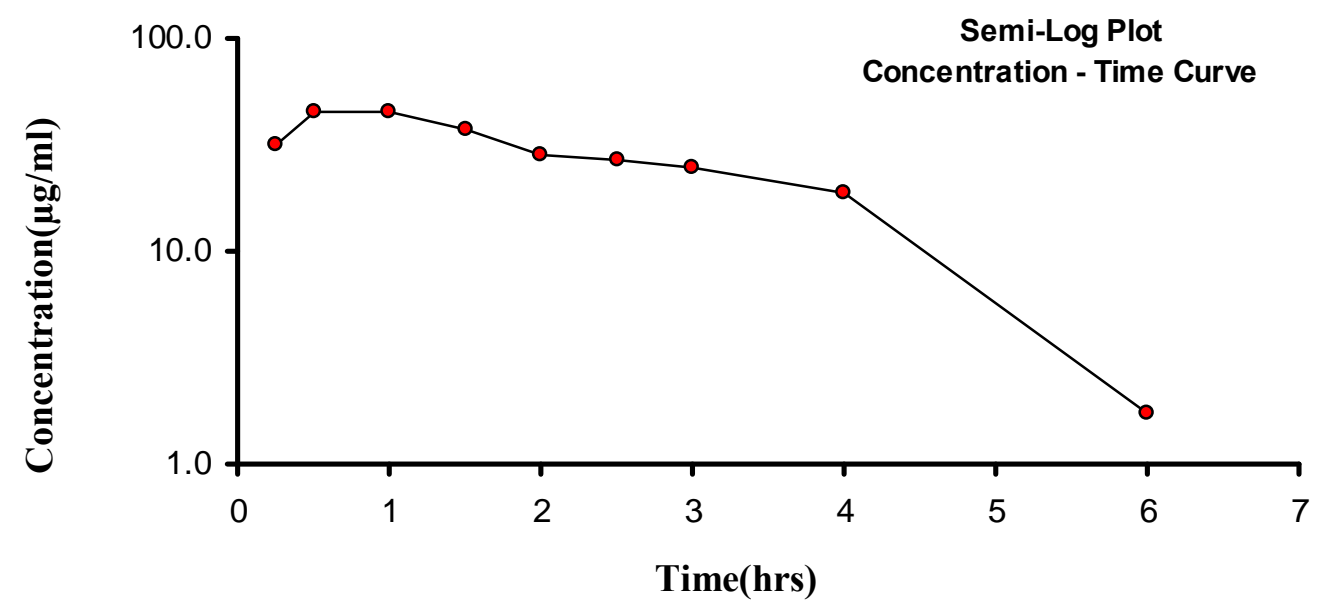

Figure 1: Semi-Log Plot of concentration-time curve for ceftriaxone in healthy Sokoto red Goats

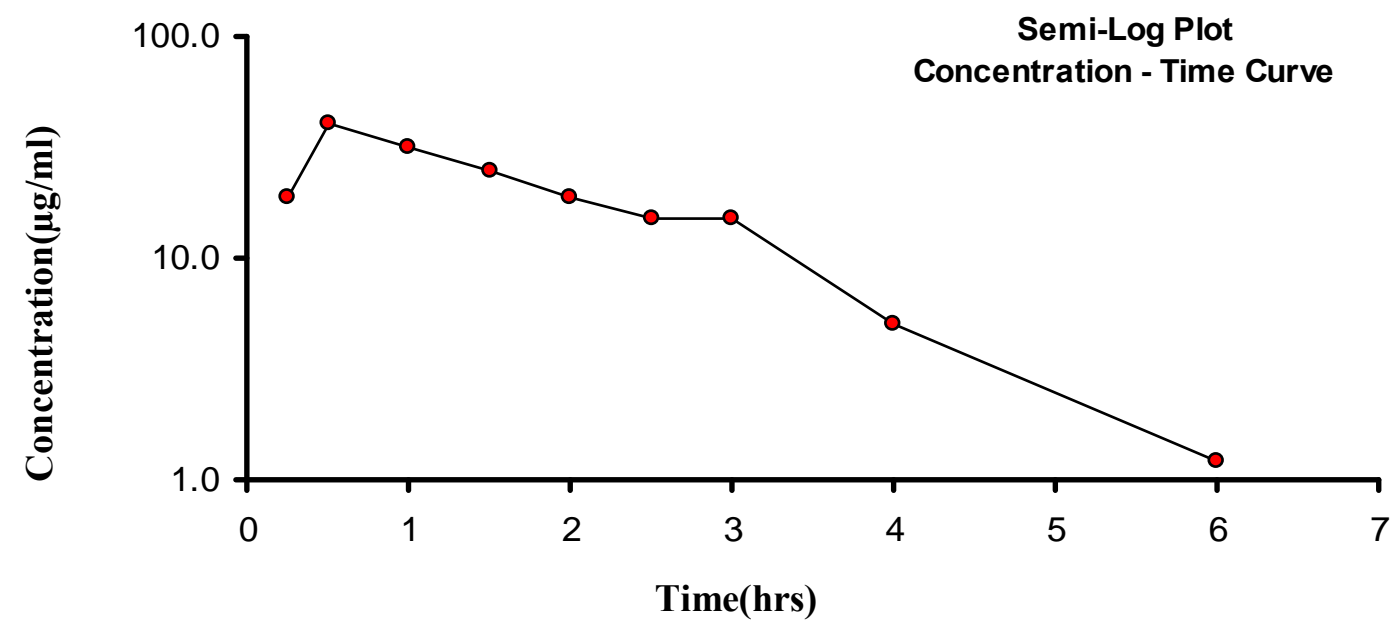

Figure 2: Semi-Log of concentration-time curve of ceftriaxone following a single intramuscular administration in $S$. thyphimurium infected Sokoto red goats. 


\section{DISCUSSION}

The effect of $S$. thyphimurium infection on the pharmacokinetics of ceftriaxone in Sokoto red goats was examined in this study with either the administration of $1 \mathrm{~g}$ ceftriaxone only or $1 \mathrm{~g}$ ceftriaxone plus inoculation with $S$. thyphimurium. S. thyphimurium infection was shown to influence the ceftriaxone plasma kinetic behavior (Table 3 ). The effect of the interaction on the maximum plasma concentrations $\left(\mathrm{C}_{\max }\right)$, absorption and elimination half life were not statistically significant $(\mathrm{P}>0.05)$; whereas there was a statistically significant effect on the area under the curve (AUC), volume of distribution $(\mathrm{Vd})$, clearance $(\mathrm{Cl})$, mean residence time (MRT) $(\mathrm{P}<0.05)$ when pharmacokinetic parameters of the healthy goats were compared with the infected (Table 3). In a similar study Etuk and Onyeyili (2006) concluded that $S$ typhimurium infection did alter the distribution of chloramphenicol, increase the loss of the drug and reduced its mean residence time in the body of the Sokoto red goats. Agerso et al., (2000) reported that the peak plasma concentration of amoxicillin remained unchanged in $S$. typhimurium infected pigs. A decrease in the peak plasma levels of chloramphenicol was observed in Pasteurella haemolytica infected calves (Burrows et al., 1986). In a similar study, a low chloramphenicol plasma level was observed in $E$. coli infected veal calves Groothuis et al., (1979). The decrease in plasma concentration observed in the infected goats may be due to fever and inflammation induced by $S$. typhimurium infection, which may be due to the decrease in the distribution phase intercept in the infected animals (Etuk and Onyeyili, 2006). Fever and inflammation are cardinal features in bacterial infection, which may inturn causes an increase in heart rate and cardiac output, increasing blood flow to the liver and kidneys, all these could lead to increase in the rate at which the drug is delivered to both organs which are important sites of drug excretion (Etuk and Onyeyili, 2006). The above may somewhat explain the increase in the total body clearance in infected goats.

\section{CONCLUSION}

This study revealed that $S$. thyphimurium infection significantly $\quad(\mathrm{p}<0.05) \quad$ influenced the pharmacokinetic parameters of ceftriaxone in
Sokoto red goats. The results of our investigations as presented in tables 2 and 3 may imply that a dose adjustment may be necessary when administering ceftriaxone in $S$. thyphimurium infected Sokoto red goats. Further studies are however required to buttress these findings and establish the mechanism of interaction.

\section{REFERENCES}

Agerso H., Friis C., and Nielsen J.P. (2000). Pharmacokinetics and tissue distribution of amoxicillin in healthy and salmonella typhimurium infected pigs. Am. J. Vet. Res. 61: $992-996$

Burrows G.E., Barto P.B., and Weeks B.R. (1986). Chloramphenicol, lincomycin, and oxytetracycline disposition in calves with experimental pneumonic pasteurellosis. $J$. Vet. Pharmacol. Therap. 9:213-222

Dasgupta A., Dennen D.A., Dean R., and McLawhon R.W. (1991). Displacement of phenytoin from serum protein carriers by antibiotics: Studies with ceftriaxone, nafcillin, and sulfamethoxazole. Clin. Chem. 37(1): $98-100$

Dezfulian M., Bitar R. A., and Bartlett J. G. (1993). Comparative efficacy of ceftriaxone in experimental infections involving Bacteroides fragilis and Escherichia coli. Chemotherapy. 39(5):355-60.

Etuk E.U. and Onyeyili P.A. (2006). The effect of salmonella infection on the plasma kinetics of chloramphenicol in the Sokoto red goats. Inter. J. of Pharmacol. 2(1):28-32

Gopal A., Charles C., Thomas B., May H., Tiwari M., Klaus S., and Charles A.B., (1994). Pharmacokinetics of ceftriaxone in patients with thypoid fever. Antimicrobial Agents and Chemotheraphy. 38(10): 2415-2418

Groothuis D.G., Gogh H.V., and Van M. (1979). The effect of Echrichia coli endotoxin induced fever on the blood levels of antimicrobial drugs after intravenous and intramuscular administration in veal calves. Trend in Vet. Pharmacol. Toxic. 6:77-86

Issa M.M., Najem R.M., El-Abadla N.S., El-Naby M.K.A., and Roshdy A.A. (2007). A comparative Pharmacokinetic Study of Two Marketed Ciprofloxacin Tablet Formulations Using Microbiological Assay. The Islamic University J.. 15(2): 189-198. 
Matzke G.R., Frye R.F., Palevsky P.M., and Joy M.S. (2000). Determinants of Ceftriaxone Clearance by Continuous Venovenous Hemofiltration and Hemodialysis. Pharmacotherapy. 20(6):635-643

Otesile E.B., Ahmed G., and Adetosoye A.I. (1990). Experimental infection of Red Sokoto goats with Salmonella typhimurium. Rev. Élev. Méd. vét. Pays trop. 43 (1): 49-53

Rawls S.M., Tallarida R., Robinson W., and Amin M. (2007). The beta-lactam antibiotic, ceftriaxone, attenuates morphine-evoked hyperthermia in rats. $\mathrm{Br}$. J. Pharmacol. 151:1095ї 1102

Sar, T.K., Mandal, T.K., Das S.K., Chakraborty A.K., and Bhattacharyya A. (2006). Pharmacokinetics of Ceftriaxone in Healthy and Mastitic Goats with Special Reference to Its Interaction with Polyherbal Drug
(Fibrosin®). Inter. J. Appl. Res. Vet. Med. 4(2):142-155

Singh R., Chaudhary R.K., and Dumka V.K. (2008). Influence of paracetamol on the pharmacokinetics and dosage regimen of ceftizoxime in cross bred calves. Israel $\mathrm{J}$. Vet. Med. 63(3):

Wang E., Bergeron Y., and Bergeron M.G. (2005). Ceftriaxone pharmacokinetics in interleukin-10-treated murine pneumococcal pneumonia. J. Antimicrobial Chemotherapy. 55(5):721-726

Zuluaga A.F., Agudelo, M., Rodriguez C.A. and Vesga O. (2009). Application of microbiological assay to determine pharmaceutical equivalence of generic intravenous antibiotics. BMC Clin. Pharmacol.. 9:1 